\title{
Twin-Studies on the Role of Non-Genetic Factors in T1D Pathogenesis
}

\section{Li-li MA ${ }^{1}$, Yan-ling $\mathrm{WU}^{2, a,{ }^{*}}$, Ying DONG ${ }^{2}$, Yoshimasa TANAKA ${ }^{3}$ and Wen ZHANG $^{1}$}

${ }^{1}$ Department of Biopharmaceutical Sciences, College of Pharmaceutical Sciences, Zhejiang University of Technology, 18 Chaowang Road, Hangzhou, 310014, China

${ }^{2}$ Virus Inspection Department of Zhejiang Provincial Center for Disease Control and Prevention, 3399 Binsheng Road, Hangzhou, 310051, China

${ }^{3}$ Center for Innovation in Immunoregulative Technology and Therapeutics, Graduate School of Medicine, Kyoto University, Kyoto, 606-8501, Japan

aylwu@cdc.zj.cn.

${ }^{*}$ Corresponding author

Keywords: Type 1 Diabetes (T1d), Twin-Study, Epigenetic Mechanism, Immunity, Complications.

\begin{abstract}
Type 1 diabetes (T1D) is a complex autoimmune disease characterized by T cell-mediated destruction of pancreatic $\beta$ cells, which is resulted from the interaction of genetic and environmental factors. Twin-study is one of the most important methods to identify the genetic basis of complex diseases or traits as well as the influence of non-genetic factors in the pathogenesis of T1D. This article summarizes recent twin-studies about the role of non-genetic factors in T1D pathogenesis, including epigenetic mechanism, immunity, and complication factors. In addition, we discuss the potential necessity of the twin-study method in the research on the influence of the living environment on T1D.
\end{abstract}

\section{Introduction}

Type 1 diabetes (T1D) is a complex autoimmune disease characterized by $\mathrm{T}$ cell-mediated destruction of pancreatic $\beta$ cells, which eventually leads to absolute deficiency of insulin [1]. Nowadays, more than 346 million people worldwide suffer from diabetes, including 20 million to 40 million patients with T1D [2, 3]. Strictly speaking, the incidence rate of T1D is increasing approximately 3-5\% per annum in recent years [4-6]. Furthermore, compared with T2D, T1D is characterized by the higher morbidity, mortality, and health care costs [3] Thus, the research on T1D pathogenesis is urgent.

At present, wide varieties of research methods have been used to explore the pathogenesis of T1D such as a population based case-control study [7], a cohort study [8], and a pedigree study [9]. Although few studies have focused on the twin cases due to the difficulty of the sample collection, the twin-study is essential to explain the influence of the various factors on the pathogenesis of T1D.

\section{Twin-Study Method}

According to the level of shared genes and the phenotypic similarity in identical twins and fraternal twins, twin-study is ideal to explore the relative contributions of genetic factors and environmental factors to phenotypic variations. It is well known that 
T1D is a complex disease caused by the combination of environmental factors and genetic predisposition [10]. T1D twin pairs can be used to examine susceptibility non-genetic factors, especially the epigenetic variation and living environment. Moreover, twin-studies on complications and immunity can not only explain the pathogenesis of complications but also provide the foundation for the immunotherapy of diabetes.

Extensive familial and population genetic studies conducted over the past 30 years have suggested that nearly $80 \%$ of T1D are likely to be related to genetic factors, indicating important roles of several risky genes in the susceptibility of diabetes [11]. However, it was also shown that non-genetic factors affect the incidence and development of T1D. The average concordance rate of T1D among twins varies from $12 \%$ to $67.7 \%$, which suggests that non-genetic factors (including epigenetic, dietary habits, and drugs) also play a key role in the pathogenesis of T1D [11]. This article summarizes recent twin-studies about the role of non-genetic factors in T1D pathogenesis, including epigenetic mechanism, immunity, and complication factors. The overview of twin-studies on T1D is shown in Table 1. In addition, we discuss the potential necessity of the twin-study method in the research on the influence of the living environment on T1D.

Table 1. Overview of twin-studies on T1D

\begin{tabular}{|c|c|c|c|}
\hline $\begin{array}{l}\text { Research } \\
\text { Contents }\end{array}$ & Samples & $\begin{array}{l}\text { Results(Comparison between the T1D affected and unaffected } \\
\text { twin) }\end{array}$ & Ref. \\
\hline \multirow[t]{4}{*}{$\begin{array}{l}\text { Epigenetic } \\
\text { Mechanism }\end{array}$} & $\begin{array}{l}52 \mathrm{MZ} \text { twin } \\
\text { pairs }\end{array}$ & A substantial enrichment of DVPs in T1D twins & [14] \\
\hline & $\begin{array}{l}9 \mathrm{MZ} \text { twin } \\
\text { pairs }\end{array}$ & $\begin{array}{c}88 \mathrm{CpG} \text { methylation sites difference } \\
\text { DNAm in HLA, INS, IL-2RB and CD226 }\end{array}$ & [15] \\
\hline & $\begin{array}{l}7 \mathrm{MZ} \text { twin } \\
\text { pairs }\end{array}$ & The global DNA hypomethylation within gene promoter regions & {$[16]$} \\
\hline & $\begin{array}{c}1 \mathrm{MZ} \\
\text { quadruplet }\end{array}$ & $\begin{array}{l}\mathrm{CD} 14^{+} \text {and } \mathrm{CD} 4^{+} \text {cells of T1D quadruplets were hyper- and } \\
\text { hypo-methylated, respectively. }\end{array}$ & [17] \\
\hline \multirow[t]{2}{*}{ Immunity } & $\begin{array}{l}5 \mathrm{MZ} \text { twin } \\
\text { pairs }\end{array}$ & \multirow{2}{*}{$\begin{array}{l}\text { The same inflammatory gene-expression levels within each twin } \\
\text { pair }\end{array}$} & {$[18]$} \\
\hline & $\begin{array}{l}10 \mathrm{MZ} \text { twin } \\
\text { pairs }\end{array}$ & & [20] \\
\hline \multirow[t]{2}{*}{$\begin{array}{l}\text { Complicatio } \\
\mathrm{n}\end{array}$} & $\begin{array}{l}5 \mathrm{MZ} \text { twin } \\
\text { pairs }\end{array}$ & \multirow{2}{*}{$\begin{array}{l}\text { The diabetes relevant gene expression differences in skin } \\
\text { fibroblasts }\end{array}$} & [22] \\
\hline & $\begin{array}{l}9 \mathrm{MZ} \text { twin } \\
\text { pairs }\end{array}$ & & [23] \\
\hline
\end{tabular}

\section{Epigenetic Mechanism}

The study of epigenetics provides an important link between the genetic susceptibility and the environment in the development of diseases. The epigenetic markers such as miRNAs have been identified, which are beneficial for therapeutic interventions and early disease diagnosis [12]. The epigenetic mechanisms that regulate the gene transcription include histone modifications and noncoding RNAs and DNA methylation [13]. DNA methylation mainly appears in the context of $\mathrm{CpG}$ dinucleotides and has been widely studied in the regulation of the gene expression in humans [13]. Recently, variability in methylated $\mathrm{CpG}$ positions (DMPs) has been shown to associate 
with a multitude of diseases, including T1D, pain sensitivity, and rheumatoid arthritis [14].

Since 2011, four groups have used the twin pairs to explore the association between the difference in DNA methylation and the susceptibility of T1D. A total of 83 monozygotic (MZ) twin pairs from European countries and the United States have been studied. Mihaela Stefan et al. [15] analyzed $9 \mathrm{MZ}$ twin pairs, in which 3 pairs discordant for T1D and 6 pairs concordant for the disease. This study identified the methylation state of $88 \mathrm{CpG}$ sites, showing a significant difference in the methylation between the affected and unaffected twins. They also found a marked difference in the DNA methylation of HLA, INS, IL-2RB and CD226 among T1D-discordant MZ twins [15]. Another study across 406,365 CpGs in 52 monozygotic twin pairs discordant for T1D in three immune effector cell types revealed a substantial enrichment of differentially variable CpG positions (DVPs) in T1D twins when compared with their healthy co-twins and healthy unrelated individuals [14]. The global DNA hypomethylation within gene promoter regions may cause T1D, but single CpG sites alone may not contribute to the onset and pathogenesis of T1D [16]. Although twin-studies on type 1 diabetes suggest that the abnormal DNA methylation might act as a pivotal part in the etiology of T1D, hypermethylation in $\mathrm{CpG}$ sites of some genes can be also observed in affected discordant twins [15]. Similarly, it was reported that CD14+ and CD4+ cells of T1D quadruplets were hyper- and hypo-methylated [17]. In order to determine whether these methylation differences trigger the onset of T1D or are merely the results after the onset of diabetes [17], it is required to monitor the level of methylation periodically and to determine the discordant years in a long-term follow-up study.

\section{Immunity}

As one of the autoimmune diseases, T1D is characterized by $\mathrm{T}$ cell-mediated destruction of pancreatic $\beta$ cells [1]. It has been demonstrated that CD4+ and CD8+ T cells are involved in immunological responses in T1D [18]. On a flow cytometric analysis and a CDR3 spectra typing of CD4+ and CD8+ T-cells from two discordant $\mathrm{MZ}$ twins and three concordant MZ twins, it was found that the repertoires of $\mathrm{T}$ cell receptors (TCR), especially CD8 T cells, were increased within each twin pair. The study suggested that in T1D MZ twins, genetic factors rather than the autoimmune disorder itself affect the TCR repertoires [19]. Similarly, in a study published in 2010, compared with healthy control twins, childhood-onset type 1 diabetic twins showed similar increased or decreased inflammatory gene-expression levels in peripheral blood monocytes [20]. In another study of V $\alpha 24 \mathrm{~J} \alpha \mathrm{T}$-cell clones activated by anti-CD3 mAb, many differences in a large number of genes in multiple pathways were found between discordant MZ twins [21]. Small samples may be one of the major potential biases of these studies.

\section{Complications}

Twin studies were also conducted to explore the mechanism underlying the complications in T1D. Two investigations of M. Luiza Caramori et al. demonstrated that the expression of diabetes-relevant genes in skin fibroblasts is different between T1D-discordant identical twins in vitro. The difference was found in a total of eight metabolic pathways: arachidonic acid metabolism, transforming growth 
factor-signaling, glutathione metabolism, glycosylphosphatidylinositol anchor, adherens junction, dorsal-ventral axis formation, proteasome, and complement and coagulation cascade. The differentially expressed pathways are highly relevant to diabetes complications, such as diabetic nephropathy [22, 23].

\section{Living Environment}

Whereas environmental factors do not change DNA sequences, they could modulate the expression of genes [24]. However, conclusive evidence about causal environmental factors in T1D pathogenesis has not been identified to date. The most likely environmental factor is congenital rubella, because children with congenital rubella syndrome eventually develop type 1 diabetes [25]. The common living environment factors, such as epigenetic [15], dietary habits [26], drugs [27], air pollutant [28], stress viral infections [29], gut microbiota [30], sunlight and Vitamin D [24], have been studied. The putative predisposing factors are viruses (enteroviruses and rotaviruses) and components of infant diet including gluten and milk. The putative protective factors are gut flora, helminths, viral infections, sunlight and Vitamin D [25]. Although no twin-study was performed so far to examine the effect of living environment on T1D, living environment factors are considered to be closely related to the incidence of T1D and cannot be ignored. It is, therefore, necessary to utilize the MZ twin series to examine the effect of living environment on T1D, so that we could understand more about how the environmental factors act on the susceptibility to the disease.

\section{Conclusions}

The epidemiological study showed that the incidence rate of childhood-onset type 1 diabetes continues to rise across Europe by an average of $3-4 \%$ per annum [1]. Therefore, the prediction and treatment of T1D is still a critical problem to be solved. Nowadays, conventional insulin therapy for T1D could make diabetic patients lead a normal life. Nevertheless, a clear understanding of the pathogenesis of T1D is urgently required for the identification of potential biomarkers and the development of immunotherapy for this disease.

Twin-studies is an ideal model to identify the potential factors that increase the risk of T1D. Recently, several MZ twin pairs with T1D have been studied. The studies mainly focused on epigenetic mechanism, immunity, and complications, which might be related to the onset of T1D. However, the twin-study method still has its own limitations, such as low representativeness and difficulty in sample collection, which would reduce the accuracy of the results.

In summary, twin series, whose genomes are identical, should be fully utilized as a T1D study model to identify potential factors that influence the risk of T1D onset.

\section{Acknowledgments}

We gratefully acknowledge the support by the Natural Science Foundation of China (21442008), International S\&T Cooperation Program of China (2015DFG32530), Natural Science Foundation of Zhejiang province (LY16H160003), the Key program co-founded by Zhejiang province and the Ministry of Health (2017192349), the Program for Zhejiang Leading Team of Science and Technology Innovation (2011R50021), and National High Technology Research and Development Program of China (863 Program) (2014AA06A514). 


\section{References}

[1] Maahs DM, West NA, Lawrence JM, Mayer-Davis EJ. Endocrinology and Metabolism Clinics of North America. 2010;39(3):481-497.

[2] Wu Y-L, Ding Y-P, Gao J, Tanaka Y, Zhang W. International journal of biological sciences. 2013;9(7):666-679.

[3] Rewers M. Diabetes and Metabolism Journal. 2012;36(2):90-97.

[4] Jarosz-Chobot P, Polanska J, Szadkowska A, et al. Diabetologia. 2011;54(3):508-515.

[5] Lawrence JM, Imperatore G, Dabelea D, et al. Diabetes. 2014;63(11):3938-3945.

[6] Patterson CC, Gyürüs E, Rosenbauer J, et al. Diabetologia. 2012;55(8):2142-2147.

[7] Arroyo-Jousse V, Garcia-Diaz DF, Codner E, Pérez-Bravo F. British Journal of Nutrition. 2016:1-8.

[8] Gao S, Wolanyk N, Chen Y, Jia S, Hessner MJ, Wang X. BMC Medical Genomics. 2017;10(1):7-7.

[9] Capasso F, Rapini N, Di Matteo G, et al. Pediatric Diabetes. 2013;14(4):304-310.

[10]Wang Z, Xie Z, Lu Q, Chang C, Zhou Z. Clinical Reviews in Allergy and Immunology. 2016:1-14.

[11] Stankov K, Benc D, Draskovic D. Pediatrics. 2013;132(6):1112-1122.

[12]Dang MN, Buzzetti R, Pozzilli P. Diabetes Metab Res Rev. 2013;29(1):8-18.

[13] Stefan M, Zhang W, Concepcion E, Yi Z, Tomer Y. Journal of Autoimmunity. 2014;50:33-37.

[14]Portela A, Esteller M. Nat Biotechnol. 2010;28(10):1057-1068.

[15]Paul DS, Teschendorff AE, Dang MA, et al. Nat Commun. 2016;7:13555-13555.

[16]Elboudwarej E, Cole M, Briggs FBS, et al. Journal of Autoimmunity. 2016;68:23-29.

[17]Disanto G, Vcelakova J, Pakpoor J, et al.. Diabetologia. 2013;56(9):2093-2095.

[18] Varela-Calvino R, Calviño-Sampedro C, Gómez-Touriño I, Cordero OJ. Archivum Immunologiae et Therapiae Experimentalis. 2017.

[19]Fozza C, Contini S, Corda G, et al. Immunobiology. 2012;217(9):920-925.

[20]Beyan H, Drexhage RC, Nieuwenhuijsen LVDH, et al. Diabetes. 2010;59(7):1751-1755.

[21] Wilson SB, Kent SC, Horton HF, et al. Proc Natl Acad Sci U S A. 2000;97(13):7411-7416.

[22] Caramori ML, Kim Y, Moore JH, et al. Diabetes. 2012;61(3):739-744.

[23] Caramori ML, Kim Y, Natarajan R, et al. The Journal of clinical endocrinology and metabolism. 2015;100(6):E883-889.

[24] Miettinen ME, Reinert L, Kinnunen L, et al. Diabetologia. 2012;55(5):1291-1294. [25]Cs K, S S. Indian J Endocrinol Metab. 2015:S58-63. 
[26] Rewers M, Ludvigsson J. The Lancet. 2016;387(10035):2340-2348.

[27] Hu Y, Jin P, Peng J, Zhang X, Wong FS, Wen L. Journal of Autoimmunity. 2016;72:47-56.

[28] Hathout EH, Beeson WL, Nahab F, Rabadi A, Thomas W, Mace JW. Pediatric diabetes. 2002;3(4):184-188.

[29] Yeung W-CG, Rawlinson WD, Craig ME. BMJ (Clinical research ed). 2011;342(5):d35-d35.

[30]Paun A, Yau C, Danska JS. J Immunol. 2017;198(2):590-595. 